\title{
Evaluation of Mandibular Condylar Morphology By Orthopantomogram In Bangladeshi Population
}

\author{
Anisuzzaman $\mathrm{MM}^{1}$, Khan $\mathrm{SR}^{2}$, Khan $\mathrm{MTI}^{3}$, Abdullah $\mathrm{MK}^{4}$, Afrin $\mathrm{A}^{5}$
}

\section{AFFILIATION:}

1. Dr. Mostafa Md. Anisuzzaman; FCPS, BDS Assistant Registrar, Department of Oral and Maxillofacial Surgery Bangladesh Dental College, Dhanmondi, Dhaka.

2. Dr. Safiquer Rahman Khan; BDS

Lecturer, Department of Oral and Maxillofacial Surgery

Bangladesh Dental College, Dhanmondi, Dhaka.

3. Dr. Mohammad Tariqul Islam Khan; DDS, BDS

Assistant Professor, Department of Oral Anatomy and Physiology Bangladesh Dental College, Dhanmondi, Dhaka.

4. Dr. Md. Kamal Abdullah; MS, BDS

Assistant Professor, Department of Orthodontics

Islami Bank Medical College, Rajshahi

5. Dr. Alia Afrin; BDS

Dental Surgeon,

The Dental Aid, Fulbari, Dinajpur, Bangladesh

\section{Article info.}

Received: $13^{\text {th }}$ November, 2018

Accepted: $15^{\text {th }}$ February, 2019

Volume: 9, Issue-1 April, 2019

DOI: https://doi.org/10.3329/updcj.v9i1.41203

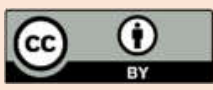

(c) Authors retain copyright and grant the journal right of first publication with the work simultaneously licensed under Creative Commons Attribution License CC - BY 4.0 that allows others to share the work with an acknowledgment of the work's authorship and initial publication in this journal.

https://creativecommons.org/licenses/by/4.0/

Publisher: Update Dental College, Dhaka, Bangladesh

Web: www.updatedentalcollege.edu.bd

E-mail: updci@hotmail.com

\author{
* Corresponding Author \\ Dr. Mostafa Md. Anisuzzaman, FCPS, BDS \\ Assistant Registrar, Department of Oral and Maxillofacial surgery \\ Bangladesh Dental College and Hospital, Dhanmondi, Dhaka \\ E-mail:dmukul808@gmail.com
}

\begin{abstract}
Background: Orthopantomograph (OPG) is one of the most common radiograph use by dental surgeon for evaluate information about teeth, Maxilla, Mandible and other bony structure. It is also available, low price and low doses of radiation. Mandibular condyle is most important landmarks of mandible, which is changes due to ageing process, developmental abnormalities, distinct diseases, trauma, endocrine shock, radio therapy etc. Panoramic radiographs remain the best screening modality for temporomandibular joint abnormalities today.

Objectives: The aims at objective of observing and documentation of shapes of condyle on an orthopantomogram, which were very important for treatment of patient in different branch of dentistry specially in oral and maxillofacial surgery.

Materials and Methods: This study composed radiographic evaluation of 500 condylar heads after imaging 250 digitalized OPGs taken for analysis. Then evaluate the mandibular condylar shape in $2 \mathrm{D}$ dimensional view (OPG).

Results: In our study, an attempt to common prevalent radiographic shapes of the condylar head on the OPG. 200 pairs of condylar heads were evaluated. Out of them $60 \%$ were oval in shape, followed by bird beak (29\%), diamond $(9 \%)$ and least being crooked finger (2\%). Oval-oval was commonly occurring mix (67\%), whereas crooked/ crooked finger was a rarity.

Conclusion: Due to low radiation exposer and availability, OPG is common chose of dentist for primary evaluate the tooth, mandible and facial skeleton. Shapes of the mandibular condyle also evaluate by OPG which showing ovaloval being most accepted in both genders.
\end{abstract}

Key words:

Mandibular condyle, Orthopantomograms,

Temporomandibular joint.

Introduction:

One of the most essential and rare joints in the body is the temporomandibular Joint (TMJ). TMJ is a voluntarily adjustable articulation between the condyle of the mandible and squamous part of the temporal bone at the base of the skull ${ }^{1}$. The function and health of TMJ is very important for life. The functions of the TMJ are to provide smooth, efficient movement of the mandible during mastication, swallowing and speech and to provide stability of mandibular position and prevent dislocation from external or unusual forces. The condyle is very special because interpretation of the mandibular growth is contributed by mandibular condyle ${ }^{2}$.

Mandibular condyles, part of the TMJ, may undergo morphological changes throughout the life mediated by functional adaptation. These changes occur more frequently after the age of 30 , causing pathologies or condylar alterations. ${ }^{3,4}$

Morphological changes of the mandibular condyle may be produced by: trauma (condylar wear), infections (osteomyelitis), genetic disorders (tumors, condylar hyperplasia) and ankylosis. These factors can alter dynamic 
functionality (opening and closing) or trigger problems such as occlusal instability, articular clicks, joint and muscle pains, TMJ alterations (reabsorption), functional problems, mandibular deviations and dislocations. ${ }^{4,5}$ The present study is aimed at observing and documentation the variation in the shapes of condyle on an OPG.

Materials and Methods:

This study composed radiographic assessment of 500 condylar heads after visualizing 250 digitalized OPGs taken for analysis. Then evaluate the mandibular condylar shapes in 2D dimensional view (OPG). All patient shows full condylar view of both sides. The OPG's of individuals with no history of TMJ trauma, surgery, dysfunction, occlusal discrepancy, and developmental anomaly were selected.

\section{Results}

Total of 500 condyles were study from 250 subjects with age ranging from 18 to 72 years, out of which 140 were males and 110 were females. (Figure 1)

A. Types of mandibular condylar shapes seen in Bangladeshi population:

1. The following shapes were perceived among the Bangladeshi population namely

(i) Oval, (ii) Bird beak, (iii) Diamond, and (iv) Crooked finger

2. The most common shape was found to be oval (68\%), followed by bird beak (20\%), diamond ( $8 \%)$, and crooked finger (4\%). (Figure 2)

3. The most common shape observed among both the males and females was the oval where $69 \%$ followed by bird beak $20 \%$ and less common crooked finger $4 \%$.

4. The combination of shapes commonly seen in male and female was oval/oval $66 \%$ followed by oval/bird $25 \%$ less common crooked finger/ crooked finger $1 \%$.

B. Mandibular condylar shapes noted in both genders were settled. As shown in Figure 3, the shapes commonly take place in both genders $47 \%$ of males and $53 \%$ of females showed oval shape suggested being most common.

C. To evaluate the common consolidation take place radiographically, the statistics as shown in Figure 4, characterize oval-oval combination was most commonly occurring $66 \%$, where as crooked finger-crooked finger appearance bilaterally was $1 \%$ observed in our study.

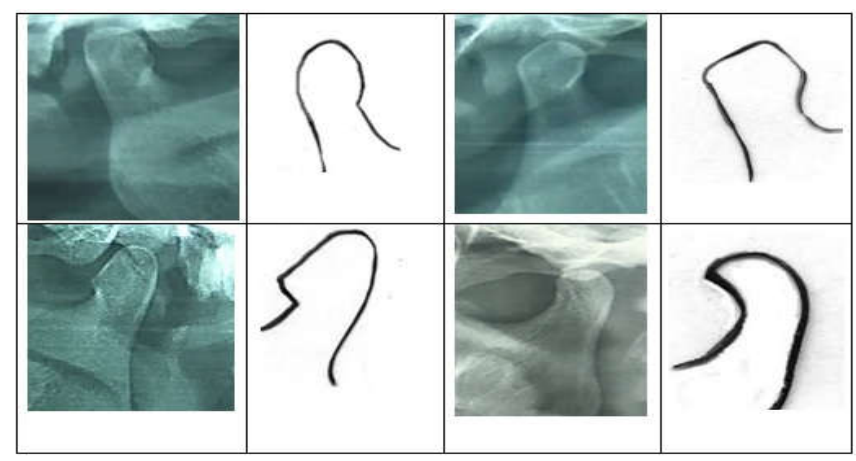

Figure 1: Different shapes of the mandibular condylar head on OPG.

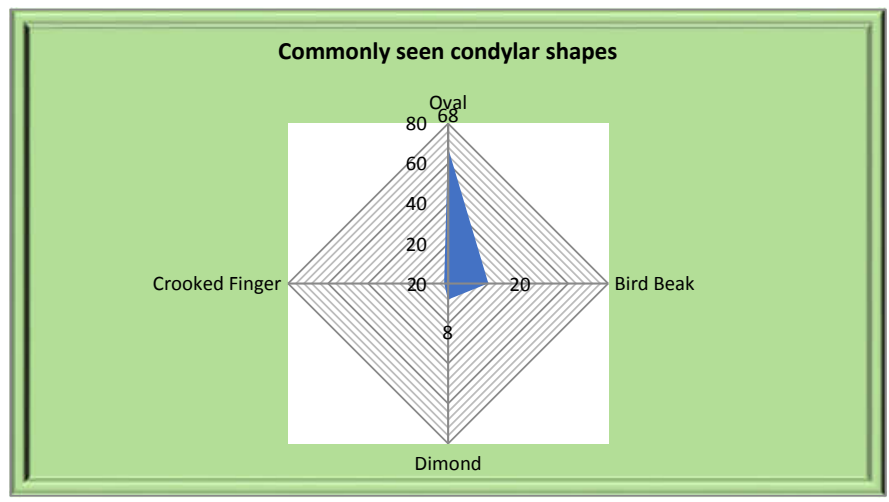

Figure 2: The percentage different of condylar shapes in Bangladeshi population.

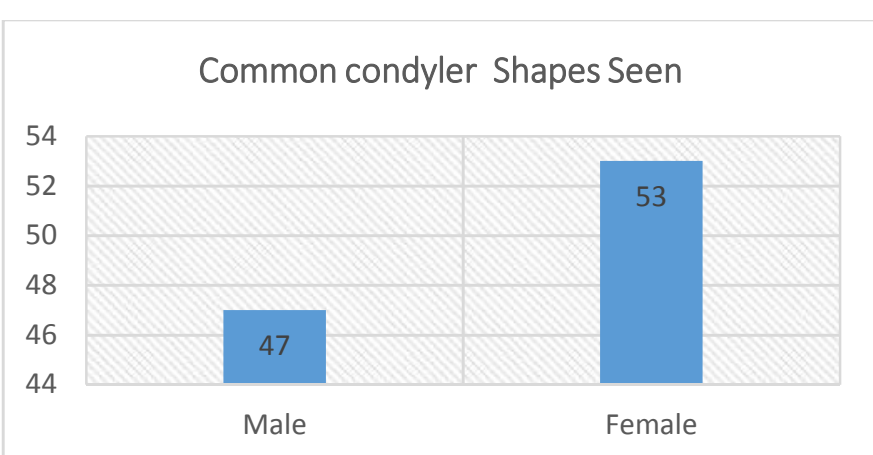

Figure: 3 Oval shapes of the mandibular condyle in Female were most common.

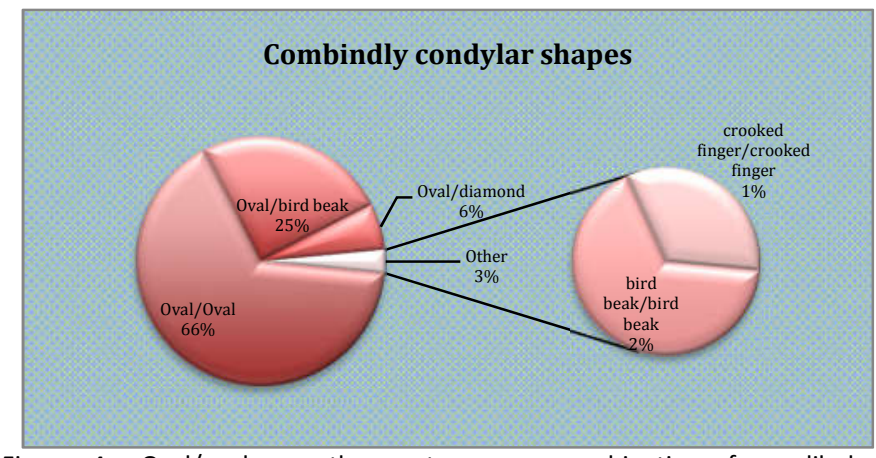

Figure: 4 Oval/oval were the most common combination of mandibular condyle shapes.

\section{Discussion}

The mandibular condyle is one of the main sites of facial growth, which is expressed in an upward and backward direction. ${ }^{6}$

The shapes of the mandibular condyle were various enormously in different age groups and individuals. Among different imaging modalities used for TMJ imaging panoramic radiographs still remains the fundamental screening modality for TMJ abnormalities. Panoramic radiograph images include both maxillary and mandibular dental arches along with other surrounding structures such as the maxillary antrum, nasal fossa, TMJ, styloid processes and hyoid bone ${ }^{7}$. 
It is a routine imaging modality used by dental surgeons for access general information about the teeth, mandible, and adjacent regions of the jaw. It also a favorable cost-benefit relationship and exposes patients to relatively low doses of radiation..$^{8,9}$ It is known that panoramic radiography is not the most appropriate method since it produces magnification and distortion in the vertical and horizontal directions. ${ }^{10}$

Low exposure dose and ease of prescription make OPG a common choice of imaging prescription. Evaluation of condyle on OPG seems to attract clinicians to make fine observations. Oval-oval being most common in both genders. More sample size and evaluation of other parameters may aid in giving more information about the population and thereby generating interest in forensics. ${ }^{11}$

In this study we evaluated the radiographic shapes of the condylar head on the OPG. The 250 pairs of condylar heads evaluated, $68 \%$ were oval in shape, followed by bird beak (20\%), diamond ( $8 \%$ ) and least being crooked finger (2\%). Ovaloval was commonly occurring combination (66\%), where as crooked/ crooked finger was $1 \%$. Again radiographs are twodimensional depiction of the three-dimensional TMJ. Hence, needs to be viewed at different positional aspect also especially knowing the tilt of the condyle anatomically. Now a day various other modalities have developed like CT scan, cone beam volumetric imaging, which can give detailed information of the condyle.

\section{Conclusion}

Limited hazard of radiation, accessible and easy to instruction makes OPG suitable for general dentist. The most familiar shape was oval, most usual combination was oval-oval in both genders. Large number of sample size and assessment of other parameters may aid in giving higher information about the population and thereby generating interest in Dentistry.

\section{References:}

1. Blasberg B, Greenberg M S. Temporomandibular disorders. In: Greenberg MS, Glick M, Ship JA, Burket's oral medicine. (11thedn), BC Decker Inc. 2008; 224-229.

2. Ross BR, Johnston MC. Developmental anomalies and dysfunction. In: Zarb GA, Carlsson GE, Sessle BJ, Mohl ND, editors. Temporomandibular Joint and Masticatory Muscle Disorders. St. Louis: Mosby; 1994. p. 221-2.

3. Park I Y, Kim JH, Park YH. Three-dimensional cone-beam computed tomography based comparison of condylar position and morphology according to the vertical skeletal pattern. Korean J Orthod. 2015;45(2):66-73. https://doi.org/10.4041/kjod.2015.45.2.66

PMid:25798412 PMCid:PMC4367133

4. Bae S, Park MS, Han JW, Kim YJ. Correlation between pain and degenerative bony changes on cone-beam computed tomography images of temporomandibular joints. Maxillofac Plast Reconstr Surg. 2017; 39(1): 19. https://doi.org/10.1186/s40902-017-0117-1

PMid:28730147 PMCid:PMC5496923

5. Hegde S, Praveen BN, Shetty SR. Morphological and Radiological Variations of Mandibular Condyles in Health and Diseases: A Systematic Review. Dentistry. 2013; 3: 154. https://doi.org/10.4172/2161-1122.1000154

6. Enlow DH. Crescimento facial. 3a ed. São Paulo: Artes Médicas; 1993. p. 8896.

7. Westesson PL. Reliability and validity of imaging diagnosis of temporomandibular joint disorder. Adv Dent Res 1993; 7: 137-51. https://doi.org/10.1177/08959374930070020401 PMid:8260001
8. Mongini F. The importance of radiography in the diagnosis of TMJ dysfunctions. A comparative evaluation of transcranial radiographs and serial tomography. J Prosthet Dent 1981; 45: 186-98.

https://doi.org/10.1016/0022-3913(81)90339-5

9. Habets LL, Bezuur JN, Jimenez Lopez V, Hansson TL. The OPG: An aid in TMJ diagnostics. III. A comparison between lateral tomography and dental rotational panoramic radiography (Orthopantomography). J Oral Rehabil 1989; 16: 401-6. https://doi.org/10.1111/j.1365-2842.1989.tb01357.x PMid:2795316

10. Laster WS, Ludlow JB, Bailey L, Hershey HG. Accuracy of measurements of mandibular anatomy and prediction of asymmetry in panoramic radiographic images. Dentomaxillofac Radiol. 2005 Nov; 34(6): 343-9. https://doi.org/10.1259/dmfr/28020783

11. Sonal V, Sandeep P, Kapil G, Christine R. Evaluation of condylar morphology using panoramic radiography. J Adv Clin Res Insights 2016; 3: 5. https://doi.org/10.15713/ins.jcri.94 